\title{
Jornalismo e corpo: um estudo sobre a representação do corpo no jornalismo de TV e na percepção de telespectadores
}

\author{
Jeferson Bertolinil
}

\section{Resumo}

Este artigo aborda o corpo retratado no jornalismo de TV no Brasil. O manuscrito usa (a) análise de conteúdo para apurar o que diz o jornalismo de TV sobre o corpo, e (b) questionários para interrogar telespectadores sobre o mesmo tema. O objetivo é alertar para uma espécie de apartheid corporal: de um lado, o corpo gordo, apresentado no discurso jornalístico como anormal; de outro, o corpo magro, retratado como normal e modelo a ser seguido. O manuscrito analisa $\mathrm{o}$ jornalismo sob o prisma da biopolítica (busca produzir corpos economicamente ativos). O texto adota técnica interdisciplinar para associar temas do Jornalismo à Filosofia e à Psicologia. Conclui que o discurso jornalístico em torno do corpo estabelece um modelo corporal compatível com a biopolítica, que resulta em estigma corporal.

Palavras-chave: Jornalismo. Televisão. Corpo.

\begin{abstract}
This article talks about the body portrayed in Brazilian television, especially in health and wellness programs. To do so, it starts from a biopolitical perspective. The aim is to alert to a kind of apartheid around the body: on the one hand, the fat body, presented on TV as abnormal; on the other, the lean body, portrayed as normal and model to be followed. The manuscript uses content analysis to determine what the media says about the body, and questionnaires to interrogate viewers about the subject. The text adopts the interdisciplinary technique to associate themes from Philosophy and Psychology to Social Communication. It concludes that the mediatic discourse around the body establishes a body model compatible with biopolitics, which results in stigma.
\end{abstract}

Keywords: Journalism. TV. Body.

\footnotetext{
1 Doutor em Ciências Humanas (UFSC), mestre em Jornalismo (UFSC), bacharel em Jornalismo (Univali). Email: jefersonbertolini@gmail.com
} 


\section{Introdução}

O corpo tornou-se objeto de um discurso jornalístico sem precedentes na TV brasileira. Na Rede Globo, observada neste trabalho, o tema aparece em programas diários, como o Bem Estar, e em quadros temáticos ou séries especiais de programas dominicais, como Fantástico.

O corpo é o nosso "eu no mundo" (MERLEAU-PONTY, 2006, p.203). É o "eixo da nossa relação com o mundo" (LE BRETON, 2006, p. 8). O "objeto suscetível de elucidar épocas e sociedades" (VIGARELLO, 2003, p.21).

No momento em que é adotado como objeto de pauta do jornalismo, o corpo firmase como aquilo que deve ser cuidado no limite. Neste cenário, "a conquista de um corpo saudável passa a ser entendida como um objetivo individual a ser atingido por meio de um exercício intencional de autocontrole, envolvendo força de vontade, restrição e vigilância constantes" (ANDRADE, 2003, p. 124).

Este trabalho analisa, especificamente, notícias referentes ao corpo apresentadas no programa Bem Estar, que está na grade de produtos jornalísticos da Rede Globo. Essas notícias, que podem ser apresentadas em reportagens, notas cobertas, entrevistas gravadas, entrevistas em estúdio etc, formam o que este manuscrito chama de discurso jornalístico.

A notícia é o instrumento mais usado pelo jornalismo de TV para falar sobre o corpo. "A notícia se traduz em informação atual, verdadeira, carregada de interesse humano e capaz de despertar a atenção de muitas pessoas" (AMARAL, 1989, p. 34). Há grande interesse do público por esse tipo de conteúdo. "As pessoas estão interessadas em notícia o tempo inteiro. Não importa se elas vêm de outras pessoas ou de veículos de comunicação de massa, todos querem saber o que está acontecendo" (SHOEMAKER; COHEN, 2006, p. 3). Particularmente, há um interesse histórico por notícias que tratam da morte ou do risco de morte. É que, por meio da morte, sabe-se também sobre a vida: aprende-se a preservá-la e a valorizá-la (STEPHENS, 1988; TRAQUINA, 2004).

Este artigo aborda o corpo retratado no jornalismo da TV brasileira a partir de uma perspectiva biopolítica. A biopolítica é uma tecnologia de poder em vigor desde o século 17. Ela procura produzir corpos economicamente ativos: 
O controle da sociedade sobre os indivíduos não se opera simplesmente pela consciência ou pela ideologia, mas começa no corpo, com o corpo. Foi no biológico, no somático, no corporal que, antes de tudo, investiu a sociedade capitalista. O corpo é uma realidade biopolítica (FOUCAULT, 2015, p. 144).

$\mathrm{Na}$ perspectiva deste trabalho, a biopolítica usa a mídia para modelar corpos, tornando-os mais eficientes. Em parte, faz isso por meio de programas jornalísticos que ensinam a cuidar do corpo.

Este estudo usa análise de conteúdo para apurar o que diz o jornalismo de TV em termos de corpo, e questionários para registrar o que pensam telespectadores de TV sobre o mesmo tema.

O objetivo do manuscrito é alertar para uma espécie de apartheid em torno do corpo promovido pelo jornalismo: de um lado, o corpo gordo, apresentado nos noticiários como perigoso ou anormal; de outro, o corpo magro, retratado como normal, como modelo a ser seguido.

O artigo está dividido em cinco sessões a partir da introdução. A primeira apresenta brevemente a televisão e seu poder de influência (a TV foi escolhida por ser o meio de comunicação mais popular do país). A segunda aborda o corpo como objeto de adoração. A terceira trata da metodologia deste estudo. A quinta destaca os resultados da análise de conteúdo do programa Bem Estar, escolhido como objeto de estudo. A sexta foca as respostas de 130 pessoas (80 assistem ao Bem Estar e 50 não assistem) via questionários.

O texto associa temas do Jornalismo à Filosofia e à Psicologia por meio de técnica interdisciplinar, usada "sempre que topamos com uma nova disciplina cujo lugar não está traçado no grande mapa dos saberes" (POMBO, 2007, p. 6).

\section{A televisão}

Este estudo considera que o discurso do jornalismo de TV relativo ao corpo (deve ser magro e rijo) exerce alguma influência na audiência. Isso porque, como se cogita desde 1920 (LASSWELL, 1938), os meios de comunicação de massa exercem alguma influência no público. O que se discute desde então é o grau de influencia:

As implicações, as influências e as consequências dos veículos de massa ainda se acham incompletamente compreendidas. Todavia, parece claro a esta altura que nossos veículos de massa influenciam suas audiências 
e a sociedade como um todo. O que não entendemos plenamente é como e até que ponto isso ocorre (DEFLEUR; BALL-ROKEACH, 1993, p. $17)$.

A televisão foi criada nos anos 1920. "Surgiu sob a égide da comercialização e para comercializar os produtos veiculados" (FEDERICO, 1983, p. 81). Em países desenvolvidos como EUA e Inglaterra, o aparelho se popularizou a partir dos anos 1940, após a Segunda Guerra Mundial (1939-1945).

Ao Brasil, a televisão chegou em 1951. O país foi o primeiro da América Latina e o quinto do mundo a ter televisão. Na década de 1960, a televisão atingiu um nível técnico melhor e se firmou como veículo publicitário. Na década de 1970, após o surgimento de emissoras pelo país, tornou-se popular: em 1971, 27\% dos lares brasileiros tinham televisão; em 1978, esse percentual saltou para $67 \%$; atualmente são $92 \%$, segundo o IBGE (Instituto Brasileiro de Geografia e Estatística).

A televisão cria uma relação de proximidade entre comunicador e receptor, e isso se reflete na adesão às suas atrações e aos personagens que exibe. Por reunir som e imagem, a televisão influi nos sentidos de atenção da audiência. "A televisão tem uma série de implicâncias psicológicas. Ao unir som, imagem e atualidade, a televisão proporciona uma relação estrita, uma sensação de estar em contato com a realidade mesma" (PINEDO, 1986, p. 63).

Pela influência na rotina do público, a televisão sempre dividiu opiniões. Os que são contra acusam-na de manipulação. "A televisão me deixou burro, muito burro demais. Agora todas as coisas que eu vejo me parecem iguais", diz a letra de Televisão, música criada pela banda de rock Titãs nos anos 1980. Os favoráveis a relacionam ao desenvolvimento social e econômico.

O impacto na sociedade, na economia, na comunidade e nos indivíduos é imensurável, e os benefícios são superiores a qualquer das disfunções da sociedade que esse avanço (tecnológico) possa ter causado. Muito embora discutidos e controvertidos, tratados como questão ética e moral, comportamental e social, o rádio e a televisão são resultado inconteste do avanço tecnológico do mundo contemporâneo (FEDERICO, 1983, p. 120).

Charaudeau (2009) diz que a união entre fala e imagem é tal na televisão que fica impossível dizer de qual delas depende a estruturação do sentido. Para o autor, a imagem produz três tipos de efeitos: efeito de realidade, quando se presume que ela reporta Revista Pauta Geral-Estudos em Jornalismo, Ponta Grossa v.5, n.2, p.255-270, Jul/Dez 2018. 
diretamente o que surge no mundo; efeito de ficção, quando tende a representar de maneira analógica um acontecimento que já passou (reconstituição); efeito de verdade, quando torna visível o que não era a olho nu (mapas, gráficos, macro e micro tomadas em close up) (CHARAUDEAU, 2009, p. 110).

Caldas (1986) afirma que a televisão exerce forte influência no público. "É claro que a televisão educa ou deseduca, informa ou desinforma. Tudo depende, evidentemente, do que ela veicula". "Se a estação de TV de capital privado elaborar uma programação cujo objetivo seja, entre outros, a educação política da sociedade, certamente ela alcançará relativo êxito" (CALDAS, 1986, p. 63).

\section{O corpo}

Objeto recorrente de pauta jornalística, o corpo parece ter se convertido em objeto de culto, como adoração permanente. Parafraseando Benjamin (2011), para quem o capitalismo é uma forma de religião com adoração permanente, é possível perceber o corpo em cinco rubricas religiosas clássicas.

A primeira é uma espécie de sensação de pertencimento à comunidade dos saudáveis. Trata-se de algo parecido com o pertencer a determinado grupo religioso: compartilha-se seus valores, seus hábitos, suas crenças, seu objeto de salvação. Nota-se, neste ponto, o que Vigarello (2003, p. 17) chama de princípio de identidade. Ou seja, a "manifestação, pelo corpo, de uma interiorização ou de um pertencimento que designa o sujeito".

A segunda está ligada à nova noção de pecado. Há dois em evidência: a gula e a preguiça. Ambos são bíblicos. Mas parecem ter sido atualizados: a noção de gula agora não está na quantidade e no exagero, mas no fato de se colocar no prato o indesejado, a gordura, o sódio, aquilo que engorda e deforma o corpo; a preguiça diz que é pecado manter parado um corpo feito para ser máquina.

A terceira tem a ver com o prazer. Assim como o sexo, que em boa parte do pensamento religioso deve ser dissociado da ideia de prazer e ser praticado apenas para a reprodução (crescei-vos e multiplicai-vos), a alimentação deve afastar-se do prazer e ser praticada apenas para a manutenção do corpo regular e produtivo.

A quarta está atrelada à ideia de culpa. Aqueles que cometem deslizes, comendo algo fora da dieta, sentem culpa. E assim como os que se arrependem do pecado devem cumprir uma penitências, quem sente culpa por um exagero alimentar busca uma Revista Pauta Geral-Estudos em Jornalismo, Ponta Grossa v.5, n.2, p.255-270, Jul/Dez 2018. 
compensação: se come pizza, fica meia hora a mais na esteira; se bebe refrigerante no almoço, caminha 20 minutos a mais no fim do dia.

A quinta está ligada ao sofrimento: exercitado no limite, o corpo é o objeto por meio do qual a pessoa se submete a uma espécie de martírio diário. A academia é o novo local onde se martiriza o corpo, como sugerem expressões do tipo "Meu Deus, não podia ser mais fácil?", “Jesus, só falta uma”, "Deus do céu, dói até a alma”, “Amém”, ao fim do exercício.

Benjamin (2011) aponta três traços da estrutura religiosa do capitalismo: o capitalismo é uma religião cultual: nada nele tem significado que não esteja em relação imediata com o culto; o culto é permanente: o capitalismo é a celebração de um culto sem trégua e sem piedade onde não há dias comuns e nenhum dia que não seja de festa; há o caráter da culpa: "uma consciência de culpa monstruosa agarra-se ao culto para fazê-la universal, martelá-la na consciência" (BENJAMIN, 2011, p. 4).

O discurso do jornalismo sobre o corpo conduz a um novo habitus do corpo.

O momento que se presencia é marcado pelo culto ao corpo magro, em forma e saudável. Por um lado ocorre a valorização da exibição de um corpo magro e que reflita saúde; por outro se destaca a epidemia da obesidade, que aumenta na medida em que as pessoas tornam-se cada vez mais sedentárias e com menos tempo para cuidar de si (JUSTO; CAMARGO, 2012, p. 21).

Para Castro (2003, p. 31), os meios de comunicação de massa representam "um dos principais meios de difusão e capitalização do culto ao corpo como tendência de comportamento" porque "medeia a temática, mantendo-a sempre presente na vida cotidiana, levando ao leitor as últimas novidades e descobertas tecnológicas e científicas, ditando e incorporando tendências".

Le Breton (2006) diz que o homem cuida do corpo porque o corpo está no centro da vida, permitindo ao indivíduo ver, ouvir, saborear, sentir, tocar e colocar significações no mundo que o cerca. É pelo corpo que o homem expressa sentimentos, interage, se relaciona com a dor e o sofrimento e participa de jogos de sedução. "Antes de qualquer coisa, a existência é corporal" (LE BRETON, 2006, p. 7).

\section{Metodologia}

Este estudo adota duas técnicas de pesquisa: análise de conteúdo e questionários. A análise de conteúdo foi usada para apurar o que diz o programa Bem Estar em termos 
de corpo magro. Foram analisados 81 programas em 2016 (33,19\% dos exibidos no ano). No critério de amostra, escolheu-se o primeiro mês cheio de cada uma das quatro estações do ano: janeiro (verão), abril (outono), julho (inverno) e outubro (primavera). "A análise de conteúdo é um conjunto de instrumentos metodológicos que se aplica a discursos extremamente diversificados. Ela absolve e cauciona o investigador pela atração pelo escondido, o latente, o não aparente" (BARDIN, 2010, p. 7). Neste estudo, destacam-se frases relativas ao corpo ditas por apresentadores, repórteres ou médicos convidados do Bem Estar. Entre parênteses, marca-se a data e o tema do programa. Não se procura contabilizar quantas referências são feitas ao corpo.

Os questionários foram utilizados para saber os que os telespectadores do programa pensam sobre o corpo gordo e o corpo magro. Foram ouvidas 80 pessoas de diferentes idades, raças, sexos, níveis de escolaridade e classe social. Os formulários foram distribuídos pela internet, via mensagens diretas de Facebook, a pessoas que comentaram, compartilharam, curtiram ou foram marcadas em postagens do Bem Estar. Para comparar, foram consultadas outras 50 pessoas, sobre o mesmo tema e com a mesma técnica de abordagem, que não assistem ao programa. Fez-se uma comparação das respostas dos dois grupos.

A quantidade de respostas obtidas não é representativa da audiência do Bem Estar e de nenhuma proporção da população brasileira. Trata-se de uma amostra por acessibilidade, na qual "o pesquisador seleciona os elementos a que tem acesso, admitindo que estes possam representar o universo" (GIL, 1995, p. 97).

A principal vantagem dos questionários é o fato de "os informantes poderem se sentir mais seguros em função de seu caráter anônimo e, com isso, se sentirem mais à vontade para expressar pontos de vista que temam colocá-los em situação problemática, constrangedora, ou que julguem não ter aprovação da maioria da sociedade" (SELLTIZ, WRIGHTSMAN e COOK, 1987, p. 17).

Outras vantagens listadas pelas autoras são o custo (costuma ser barato aplicálos), o conforto ao pesquisado (não precisa responder de pronto, sob pressão) e precisão (evita vieses potenciais do entrevistador).

\section{O que diz o Bem Estar sobre o corpo}

O programa Bem Estar valoriza quem leva uma vida saudável. Os entrevistados elogiam quem almoça vegetais, quem para de fumar, quem caminha diariamente. Revista Pauta Geral-Estudos em Jornalismo, Ponta Grossa v.5, n.2, p.255-270, Jul/Dez 2018. 
Enaltecem, sobretudo, quem perde peso. O corpo magro e saudável aparece como norma.

O televisivo enaltece a magreza ao ensinar a "comer sem engordar" ou a comer menos. "No próximo bloco vamos falar de um aliado da cozinha: o vinagre. Com ele dá para proteger os alimentos e ainda comer sem engordar", diz o apresentador Fernando Rocha (13/01, sobre conservantes); "O tomate ajuda a não engordar", diz Rocha (11/01, sobre macarrão); "Daqui a pouquinho a gente vai dar dica de ouro para você comer sem engordar", diz Rocha (04/07, sobre trabalho que engorda). "Sabia que comer casca de fruta ajuda a controlar o colesterol? É a nossa dica de hoje no quadro comer sem engordar", diz a apresentadora Michele Loretto (21/04, sobre colesterol); "Alimentos crocantes e durinhos aumentam a saciedade. A pessoa acaba comendo menos", diz nutricionista (18/01); "Mastigue lentamente, isso ajuda a comer menos", diz médica $(18 / 01)$.

A magreza é festejada como sinônimo de beleza ou como boa notícia. "Até porque, se ela malha [telespectadora], é porque quer ficar bem [bonita] e não quer engordar", diz a apresentadora Mariana Ferrão (18/01, sobre comer à noite); "A boa notícia é que você está mais magro", diz nutricionista ao apresentador Fernando Rocha, após ele se pesar em programa de emagrecimento (25/07, sobre IMC).

Busca-se espantar a gordura: "Prefira milho sem manteiga porque a gente não quer gordura", diz pediatra (21/01, sobre comida de praia); "Bacon? Socorro", exclama médico sobre alimentos que causam colesterol (26/01, sobre colesterol); "Olha só que coisa abençoada: além de ficar mais gostoso, quando você coloca o queijo, diminui o índice glicêmico", diz Fernando Rocha ao botar queijo no pão (carboidrato puro eleva o pico glicêmico) (19/04, sobre doces); "Você gosta de picolé", pergunta Fernando. "Adoro. Sem engordar, melhor ainda", reponde Mariana (05/01, sobre água de coco); "Você vai ajudar quatro gordinhos. Você vai ajudar que eles não tenham mais este título", diz Fernando Rocha, ao pedir votos aos candidatos do reality de emagrecimento (29/04, sobre emagrecimento); "Eu estou gorducho, eu estou uma bolota, uma porpeta, uma almôndega. Ai meu Deus, que tristeza", diz Loro José, o papagaio da apresentadora Ana Maria Braga, do Mais Você, entrevistado em reportagem sobre comida no trabalho (04/07, sobre trabalho que engorda); "Aqueles pneuzinhos [gordura abdominal] que ninguém gosta de ter são triglicerídeos", diz médica (21/04, sobre colesterol); "Meu marido não consegue me pegar no colo. Não consigo amarrar meu tênis. Não consigo deitar com meu Revista Pauta Geral-Estudos em Jornalismo, Ponta Grossa v.5, n.2, p.255-270, Jul/Dez 2018. 
marido no sofá", diz mulher que quer participar de reality de emagrecimento (29/04, sobre emagrecimento).

O programa valoriza o corpo mediano. "A gente pegou assim uma média de um peso feminino. Temos aqui uma mulher elegante, esbelta, que pesa $68 \mathrm{~kg}$. Ela vai precisar de 68 gramas de proteína", diz Fernando Rocha. "Vamos pegar o modelo masculino: um rapaz saudável de 90 kg", diz o apresentador (01/07, sobre lanches).

O gordo pode ser visto como alguém anormal: "O obeso ganha menos que uma pessoa normal [o gordo não é normal?]", diz médico (04/07, sobre trabalho que engorda); "Pessoa normal", diz texto de infográfico sobre hormônios; "Obeso" é como o mesmo infográfico se refere às demais pessoas (18/07, sobre tratamento para emagrecer) [ou seja, o mundo, para o programa, é dividido entre normais e obesos].

O magro, embora possa ter mais doenças que o gordo, como colesterol, é visto como saudável. O gordo aparece como doente: "Uma pessoa magra, saudável, come este pedacinho e fica satisfeito. Já um obeso pode comer dois bolos", diz Fernando, em tom de reprovação (18/07, sobre tratamento para emagrecer).

Este discurso parece refletir entre os telespectadores, que enviam mensagens dizendo que gostariam de perder peso: "O meu grande sonho na vida é pesar menos de 100 kg", diz humorista obeso (25/07, sobre IMC); "Me sinto muito bem estando leve", diz mulher que emagreceu $30 \mathrm{~kg}$ (28/04, sobre Parkinson).

\section{O que dizem os que "assistem" e os que "não assistem" ao Bem Estar}

Em relação ao corpo gordo, os 130 participantes ouvidos por questionários (80 que assistem ao Bem Estar e 50 que não assistem ao programa) responderam à seguinte pergunta: você acredita que "os outros" definem a pessoa "gorda" como? Com base em pesquisas anteriores, foram oferecidas estas alternativas: alguém comum, com peso diferente do da maioria; alguém doente; malandro; preguiçoso; sedentário; alguém não se cuida. A pergunta invocando a opinião dos "outros" e não diretamente do respondente é, em técnica psicológica, chamada de zona muda. Trata-se de uma forma de deixar o respondente à vontade e de colher, indiretamente, uma resposta que seria dele.

\section{Gráfico 1: percepção sobre como os "outros" definem a pessoa "gorda"}




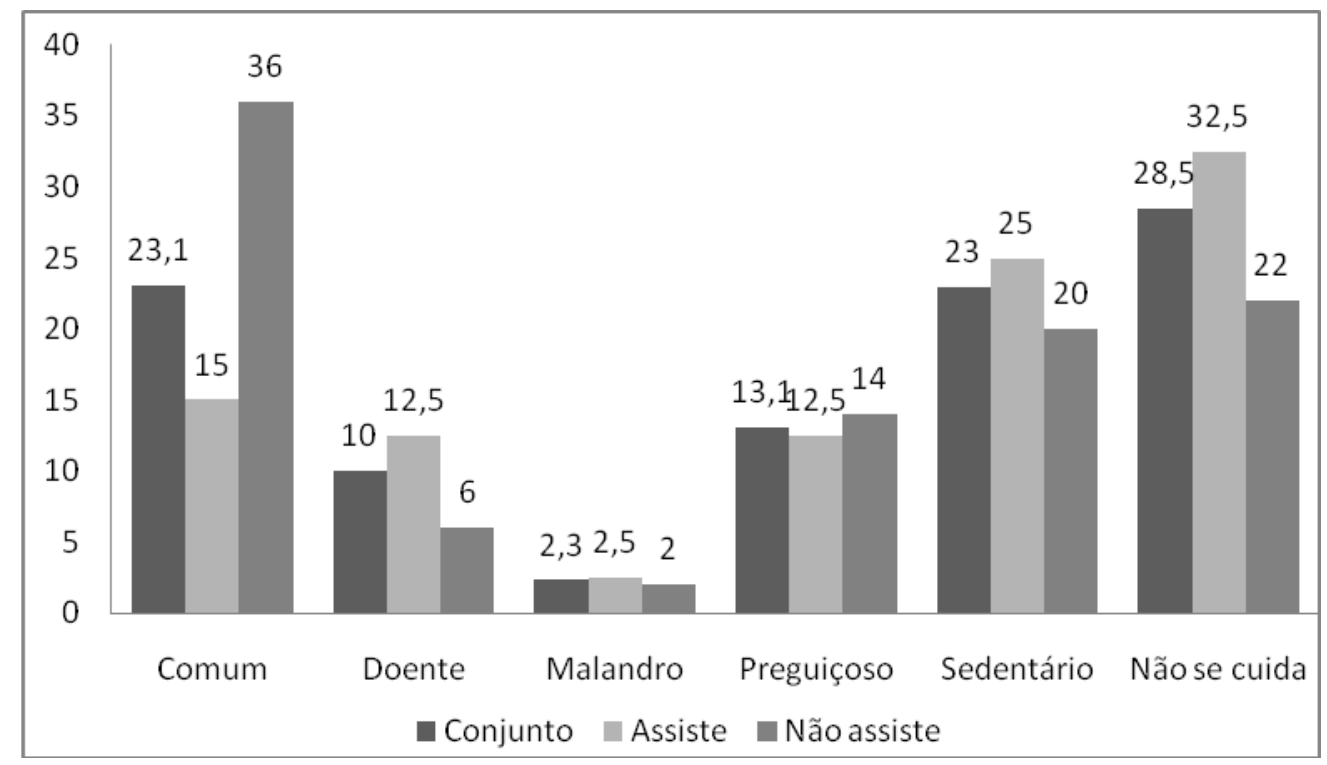

Fonte: elaborado pelo autor

No plano geral, somando as respostas dos que assistem ao Bem Estar e dos que não assistem, a resposta mais comum foi "alguém que não se cuida" $(28,5 \%)$, seguida de "alguém comum, com peso diferente do da maioria" (23,1\%), "sedentário" (23\%), "preguiçoso" (13,1\%), "alguém doente" (10\%) e "malandro" $(2,3 \%)$.

No comparativo entre os grupos, três dados chamam atenção: a diferença no percentual das opções "alguém comum, com peso diferente do da maioria", "alguém que não se cuida" e "doente".

Entre os respondentes que "assistem" ao Bem Estar, apenas 15\% marcaram a primeira opção, contra $36 \%$ do segundo grupo; $32,5 \%$ dos que "assistem" marcaram a opção "alguém que não se cuida"; contra 22\% do segundo grupo; e 12,6 dos que "assistem" responderam "doente", contra apenas $6 \%$ dos que "não assistem".

As respostas permitem duas leituras básicas. A primeira é que, no conjunto, verifica-se que os respondentes demonstram uma rejeição à gordura, um dos alvos principais dos programas sobre saúde e bem estar (só $23 \%$ marcaram a opção gordo é "alguém comum, com peso diferente do da maioria"). A segunda é que, no comparativo, verifica-se uma percepção antigordura maior entre os respondentes que "assistem" ao Bem Estar. Apenas 15\% consideram que, para os outros, gordo é "alguém comum, com peso diferente do da maioria", contra $36 \%$ dos que "não assistem" ao programa. Outra: $32,5 \%$ dos respondentes que "assistem" consideram que, para os outros, gordo é "alguém 
que não se cuida", contra $22 \%$ dos que "não assistem". Pelos dados, poderia se considerar que os respondentes mais expostos ao programa percebem nos "outros" (ou demonstram) mais aversão à gordura. Este grupo também percebe nos "outros" (ou demonstra) mais rigor em termos de cuidados pessoais. Esse comportamento leva a crer que o mantra da televisão sobre gordura (deve ser combatida) e cuidados pessoais (devem ser valorizados) tem potencial para ser incorporado pela audiência.

Em relação ao corpo magro, os participantes foram convidados a responder à seguinte pergunta, também com zona muda: você acredita que, para "os outros", o que é "ser magro"? Com base em estudos anteriores, foram oferecidas as seguintes alternativas: um padrão; uma obrigação que tentam me impor; ser saudável; ser bonito; ser feliz; outro.

Gráfico 2: percepção sobre como o que é "ser magro"?

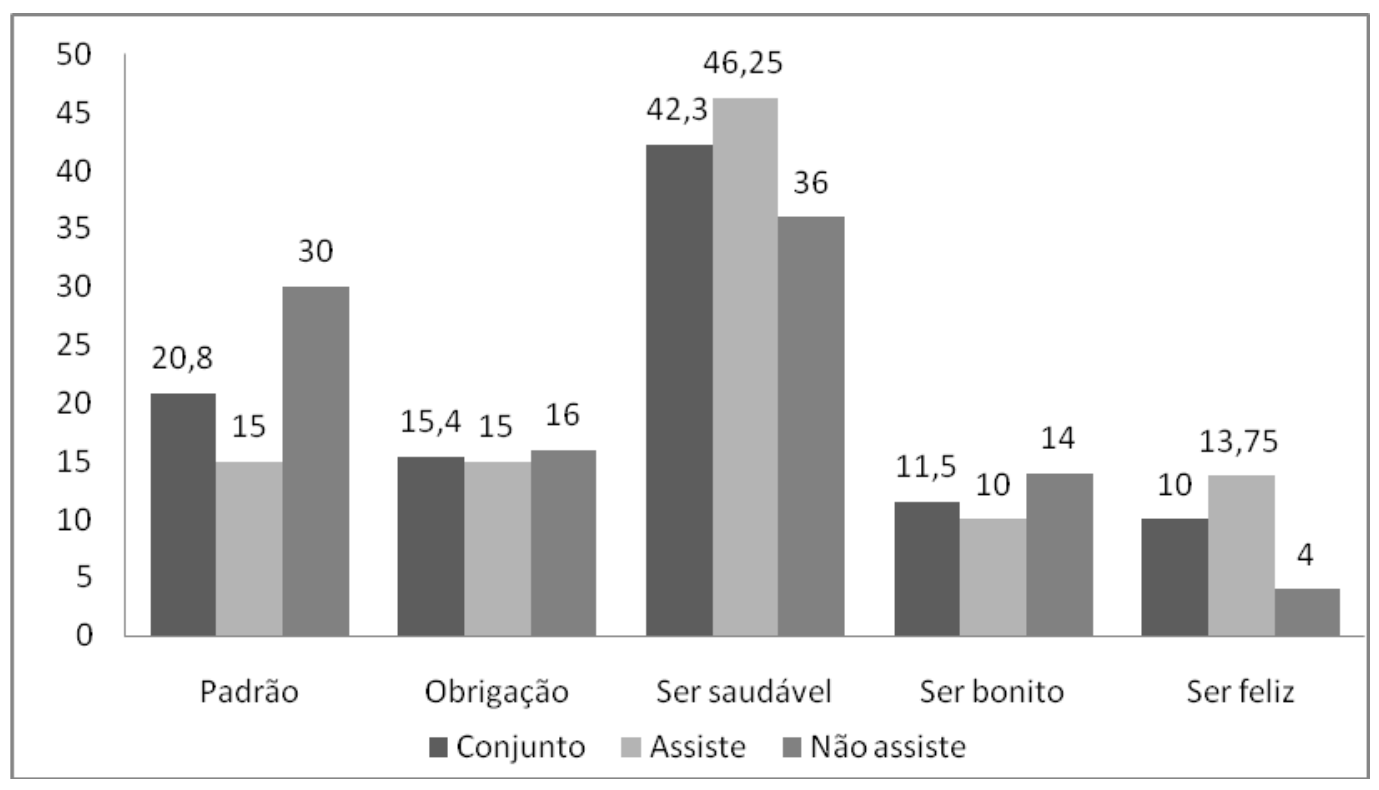

Fonte: elaborado pelo autor

No conjunto dos dois grupos, a resposta mais comum foi "ser saudável" $(42,3 \%)$, seguida de "padrão" (20,8\%), "obrigação que tentam me impor" (15,4\%), "ser bonito" $(11,5 \%)$ e "ser feliz" (10\%).

No comparativo, três dados chamam a atenção: 15\% dos que "assistem" ao programa Bem Estar responderam que, para "os outros", "ser magro" é um "padrão", contra $30 \%$ dos que "não assistem"; $13,75 \%$ dos que "assistem" responderem que, para "os outros", ser magro é "ser feliz", contra apenas 4\% dos que "não assistem"; e 46,25\% Revista Pauta Geral-Estudos em Jornalismo, Ponta Grossa v.5, n.2, p.255-270, Jul/Dez 2018. 
dos respondentes do primeiro grupo responderam que, para "os outros", "ser magro" é ser saudável, contra $36 \%$ dos participantes do segundo grupo.

As respostas levam a duas leituras básicas. A primeira é que, no conjunto, verificase entre os respondentes uma associação da magreza à saúde, o que nem sempre faz sentido (pode-se ter níveis altíssimos de colesterol sendo magro). Nota-se, também, entre os respondentes, uma noção de que, em tempos de valorização e exibição do corpo, a magreza aparece como um "padrão", ou seja, como algo que externamente tenta-se impor, como um molde. A segunda é que os respondentes mais expostos à mídia demonstram ter menos noção de que a magreza pode ser "um padrão", possivelmente influenciados pelo discurso midiático que diz que a magreza, em certo sentido, é sinal de saúde. Estes respondentes, três vezes mais que os integrantes do outro grupo, considerarem que "ser magro" é sinônimo de felicidade. Em resumo, os números indicam que, entre os respondentes mais interessados no tema "saúde", a televisão cria a ideia de que a magreza não é um padrão que deve ser seguido (algo que engessa vontades), mas sinônimo de saúde e de felicidade.

\section{Conclusão}

Ao condenar a gordura e ao estimular a magreza, o jornalismo de TV ajuda a criar uma norma corporal (produz ou faz circular um formato corpóreo tido como ideal e como modelo a ser copiado). Este tipo de norma é compatível com a biopolítica porque rege os indivíduos por meio de um modelo, tentando torná-los mais eficientes do ponto de vista econômico.

Uma consequência possível deste processo é uma espécie de apartheid corporal: de um lado, o corpo magro, apresentado na TV como normal; de outro, o corpo gordo, que, desencorajado na tela da TV, passa a ser encarado como anormal.

Em meio ao boom saudável visto no jornalismo de TV, o corpo magro parece ter se convertido em sinônimo de beleza, em garantia de asseio, de apreço pessoal, ao passo que o corpo gordo parece associado à doença, pessoa relaxada, malandra ou descuidada.

Sob um olhar biopolítico, poderia se considerar que a gordura parece inserida em uma espécie de racismo. "Quanto mais as espécies inferiores tenderem a desaparecer, quanto mais os indivíduos anormais forem eliminados, menos degenerados haverá em 
relação à espécie, mais eu viverei, mais forte serei, mais vigoroso serei, mais poderei proliferar" (FOUCAULT, 2010, p. 215).

A gordura já foi sinal de riqueza (FISCHLER, 1995; POULAIN, 2013). Mas, no momento em que se valoriza o corpo magro e exercitado, converteu-se em uma espécie de estigma: ninguém quer ser gordo. "Estigma é a situação do indivíduo que está inabilitado para a aceitação social plena" (GOFMANN, 1988, p. 7).

O termo estigma foi criado pelos gregos para se referir a sinais corporais com os quais se procurava evidenciar alguma coisa de extraordinário ou de ruim sobre o status moral de quem os apresentava. Esses sinais eram feitos com cortes ou fogo no corpo e avisavam que o portador era um escravo, um criminoso ou um traidor. Uma pessoa marcada era considerada ritualmente poluída e deveria ser evitada, especialmente em público (GOFMANN, 1988).

Independentemente do motivo, o estigma surge de pré-concepções sobre o outro. Nasce do lapso entre a identidade social virtual (aquela que imaginamos sobre alguém) e a identidade social real (aquela que nos é apresentada). O estigmatizado costuma ter um atributo que o torna diferente de outros que se encontram em uma categoria em que pudesse ser incluído, sendo, até, de uma espécie menos desejável. "Deixamos de considerá-lo criatura comum e total, reduzindo-o a uma pessoa estragada e diminuída" (GOFMANN, 1988, p. 13).

O autor observa que o indivíduo estigmatizado tende a ter as mesmas crenças sobre sua identidade que os outros têm, e que a pessoa estigmatizada pode ter uma falsa sensação de aceitação porque há uma tendência de gentileza para com o diferente. "Deve-se ver, então, que a manipulação do estigma é uma característica geral da sociedade, um processo que ocorre sempre que há normas de identidade. $O$ estigmatizado e o normal são parte um do outro" (GOFMANN, 1988, p. 141-146).

A estigmatização pode ser compreendida como um processo dinâmico e contextual, produzido socialmente, moldado por forças históricas e sociais, moderado por efeitos imediatos do contexto social e situacional sobre a perspectiva do estigmatizador, estigmatizado e da interação entre os dois. Considera-se este processo como capaz de gerar consequências sociais no âmbito afetivo, cognitivo e comportamental. "Dentre elas, perda de status, redução da autoestima, expectativas de rejeição prejudiciais a interações sociais e isolamento" (SILVEIRA; SOARES; GOMIDE; RONZANI, 2011, p. 132). 
A aversão à gordura é incitada pelo discurso jornalísitico. Esse discurso é compartilhado com amigos e aos poucos vai formando uma representação social sobre a gordura. Trata-se de uma espécie de senso comum que nasce das falas cotidianas (MOSCOVICl, 1981, p, 181).

Os meios de comunicação de massa podem influir na formação de determinada representação social. Significa que, se direta ou indiretamente atacam o sobrepeso, podem ajudar a formar esta ideia na audiência. "A formação de uma representação social passa por trocas e por influências recíprocas entre os jornais e seus leitores" (CLÉMENCE; GREEN; COURVOISIER, 2011, p. 142).

Os veículos e produtos de mídia atuam principalmente na edificação da conduta, da opinião, da atitude e do estereótipo. "A comunicação social, sob seus aspectos interindividuais, institucionais e midiáticos, aparece como condição de possibilidade e de determinação das representações e dos pensamentos sociais" (JODELET, 2001, p. 30).

\section{Referências}

AMARAL, Luiz. Técnica de jornal e periódico. Rio de Janeiro: Tempo Brasileiro, 1989

ANDRADE, Sandra dos Santos. Saúde e beleza do corpo feminino: algumas representações no Brasil do Século XX. Porto Alegre, v. 9, n.1, 2003

BARDIN, Laurence. Análise de conteúdo. Lisboa: Edições 70, 2010

BENJAMIN, Walter. Capitalismo como religião; tradução de Jander de Melo Marques Araujo. Revista Garrafa 23, 2011

CALDAS, Waldenyr. Cultura de massa e política de comunicações. São Paulo: Global, 1986

CAMARGO, Brigido; JUSTO, Ana Maria; ALVES, Catarina Durante Bergue; SCHLOSSER, Adriano. Efeitos de contexto interacional e comunicação nas representações sociais sobre o corpo. Psicologia e Saber Social, v. 2, 2013

CASTRO, Ana Lúcia de. Culto ao corpo e sociedade. São Paulo: Fapesp/Annablume, 2003

CHARAUDEAU, Patrick. Discurso das mídias; tradução de Angela Corrêa. São Paulo: Contexto, 2009

CLÉMENCE, Alain; GREEN, Eva; COURVOISIER, Nelly. Comunicação e ancoragem: a difusão e a transformação das representações. In: Teoria das representações sociais: 50 anos. Brasília: Technopolitk, 2011 
DEFLEUR, Melvin. BALL-ROKEACH, Sandra. Teorias da Comunicação de massa; tradução de Otávio Alves Velho. Rio de Janeiro: Jorge Zahar Editor, 1993

FEDERICO, Maria Elvira Bonavita. História da comunicação: rádio e TV no Brasil. Petrópolis: Vozes, 1983

FISCHLER, Claude. El (h) omnívoro: el gusto, la cocina y el cuerpo; tradução de Mario Merlino. Barcelona: Anagrama, 1995

FOUCAULT, Michel. Em Defesa da Sociedade. 2 ed; tradução de Maria Ermantina Galvão. São Paulo: Martins Fontes, 2010

$\overline{\text { e Terra, }} 2015$

Microfísica do poder; tradução de Roberto Machado. 2 ed. Rio de Janeiro: Paz

GIL, Antônio Carlos. Métodos e técnicas de pesquisa social. 4. ed. São Paulo: Atlas, 1995

GOFFMAN, Erving. Estigma: notas sobre a manipulação da identidade deteriorada. 4. ed. Rio de Janeiro: Guanabara, 1988

JODELET, Denise. Representações Sociais: um domínio em expansão. In: JODELET, Denise (org). As representações sociais. Rio de Janeiro: EdUFRJ, 2001

LASSWELL, Harold. Propaganda technique in the word war. Nova York: Peter Smith, 1938

LE BRETON, David. A sociologia do corpo. 2 ed; tradução de Sônia Fuhrmann. Petrópoles: Vozes, 2006

MERLEAU PONTY, Maurice. Fenomenologia da percepção. $3^{a}$ ed. São Paulo: Martins Fontes, 2006

MOSCOVICl, Serge. On social representation. In: FORGAS, Joseph (org). Social cognition. London: Academic Press, 1981

PINEDO, Amaro La Rosa. Psicologia de la comunicación masiva. Lima: La Gaceta, 1986

POMBO, Olga. Epistemologia da Interdisciplinaridade. Conferencia proferida no Colóquio Interdisciplinaridade, Humanismo e Universidade, promovida pela Cátedra Humanismo Latino, Porto, 2007

POULAIN, Jean-Pierre. Sociologias da alimentação: os comedores e o espaço social alimentar. 2. ed; tradução de Rossana Pacheco da Costa Proença, Carmen Sílvia Rial e Jaimir Conte. Florianópolis: Editora UFSC, 2013

SHOEMAKER, Pamela; COHEN, Akiba. News around the world. London: Routledge, 2006 
SELLTIZ, Claire. WRIGHTSMAN, Lawrence Samuel. COOK, Stuart Wellford. Métodos de pesquisa nas relações sociais; 4. ed. São Paulo: EPU, 1987

SILVEIRA, Pollyanna Santos da; MARTINS, Leonardo Fernandes; SOARES, Rhaisa Gontijo; GOMIDE, Henrique Pinto; RONZANI, Telmo Mota. Revisão sistemática da literatura sobre estigma social e alcoolismo. In: Estudos de psicologia, n. 16, 2011

STEPHENS, Mitchell. History of news: from the drum to the satellite. Nova York: Viking Press, 1988

TRAQUINA, Nelson. Teorias do jornalismo: a tribo jornalística: uma comunidade interpretativa internacional. Florianópolis: Insular, 2004

VIGARELLO, Georges. A história e os modelos do corpo. Pro-Posições. Unicamp, v.14, n.2, 2003

Recebido em: 03/09/2018

Publicado em: 21/12/2018 